\title{
Overexpression of AtAHL20 causes delayed flowering in Arabidopsis via repression of FT expression
}

Reuben Tayengwa ${ }^{1,2,3^{*}}$ (D), Pushpa Sharma Koirala ${ }^{2,4}$, Courtney F. Pierce ${ }^{2,5}$, Breanna E. Werner ${ }^{2,6}$ and Michael M. Neff ${ }^{1,2}$

\begin{abstract}
Background: The 29-member Arabidopsis AHL gene family is classified into three main classes based on nucleotide and protein sequence evolutionary differences. These differences include the presence or absence of introns, type and/or number of conserved AT-hook and PPC domains. AHL gene family members are divided into two phylogenetic clades, Clade-A and Clade-B. A majority of the 29 members remain functionally uncharacterized. Furthermore, the biological significance of the DNA and peptide sequence diversity, observed in the conserved motifs and domains found in the different AHL types, is a subject area that remains largely unexplored.

Results: Transgenic plants overexpressing AtAHL2O flowered later than the wild type under both short and long days. Transcript accumulation analyses showed that 35S:AtAHL20 plants contained reduced FT, TSF, AGL8 and SPL3 mRNA levels. Similarly, overexpression of AtAHL20's orthologue in Camelina sativa, Arabidopsis' closely related Brassicaceae family member species, conferred a late-flowering phenotype via suppression of CSFT expression. However, overexpression of an aberrant AtAHL20 gene harboring a missense mutation in the AT-hook domain's highly conserved R-G-R core motif abolished the late-flowering phenotype. Data from targeted yeast-two-hybrid assays showed that AtAHL20 interacted with itself and several other Clade-A Type-I AHLs which have been previously implicated in flowering-time regulation: AtAHL19, AtAHL22 and AtAHL29.

Conclusion: We showed via gain-of-function analysis that AtAHL2O is a negative regulator of FT expression, as well as other downstream flowering time regulating genes. A similar outcome in Camelina sativa transgenic plants overexpressing CSAHL2O suggest that this is a conserved function. Our results demonstrate that AtAHL2O acts as a photoperiod-independent negative regulator of transition to flowering.
\end{abstract}

Keywords: AHL, AHL20, Arabidopsis, AT-hook, Flowering, FT

\section{Background}

The 29-member Arabidopsis AT-HOOK MOTIF CONTAINING NUCLEAR LOCALIZED (AHL) gene family is found in all sequenced plant species, ranging from the

\footnotetext{
* Correspondence: reubent@umd.edu

${ }^{1}$ Program in Molecular Plant Sciences, Washington State University, Pullman, WA 99164, USA

²Department Crop and Soil Sciences, Washington State University, Pullman, WA 99164, USA

Full list of author information is available at the end of the article
}

moss Physcomitrella patens to flowering plants such as Arabidopsis thaliana, Sorghum bicolor, Zea mays and Populus trichocarpa $[49,50]$. AHL proteins are characterized by two conserved structural units: the AT-hook motif and the PLANT AND PROKARYOTE CONSERVED (PPC) domain $[1,12]$.

The AT-hook is a small DNA-binding protein domain which was first characterized in the HIGH MOBILITY GROUP (HMG) non-histone chromosomal protein 
HMG-I(Y), AHL homologues in mammals [1]. Arabidopsis AHLs contain a conserved arginine-glycinearginine-proline (R-G-R-P) core motif in the AT-hook domain $[35,49,50]$. When AT-hook domain sequences from all sequenced land plant species are aligned, only arginine-glycine-arginine (R-G-R) amino acid residues remain $100 \%$ conserved, suggesting that they are important for function [50]. Studies in HMG proteins and AThook motif-containing peptides showed that the AThook domain binds to the minor groove of AT-rich DNA via the R-G-R motif $[1,18,32,33]$. Mutations in this core motif have been shown to abolish DNA binding as well as AHL protein function [14, 17, 35, 47, 49].

Arabidopsis AHLs evolved into two major phylogenetic clades: Clade-A and Clade-B [49]. Clade-A and Clade-B $A H L s$ underwent multiple gene duplication events which resulted in the expansion of the gene family [50]. Functional characterization of single and multiple gene lossof-function mutants suggest that genetic redundancy exists among multiple $A H L$ genes in Arabidopsis [35, 40, 49]. In previous $A H L$ gene knockout studies, single $T$ DNA insertion mutants including ahl22-1 [40], sob3-4 and esc-8 [35] did not show obvious phenotypes, unless other closely related family members were also knocked out. Zhao et al. [49] reported that when specific $A H L$ genes were knocked out in higher order combinations, such as in the quadruple sob3-4 esc-8 ahl6 ahl22, the resultant plants showed more dramatic phenotypes compared to lower order gene knockout mutant combinations. Furthermore, Zhao et al. [49] also showed that sob3-6, a dominant negative mutant carrying a missense allele in the R-G-R core of the AT-hook motif, displayed more dramatic hypocotyl phenotypes compared to the sob3-4 esc-8 ahl6 ahl22 quadruple mutant. Based on these data, a molecular model was proposed where AHLs interact with each other and themselves, as well as other nuclear proteins, such as transcription factors (TFs), to form a "DNA-AHL-TF complex" [49]. Overall, these data suggest that genetic redundancy exists among AHLs. It is hypothesized that most AHLs function as complexes, and that mutations in the DNA-binding AThook motif may render that entire complex nonfunctional [49].

Both loss-of-function and gain-of-function studies in Arabidopsis have demonstrated a role for $A H L s$ in plant growth and developmental processes, including auxin, brassinosteroid and gibberellic acid signaling, hypocotyl elongation, petiole growth, root system architecture, environmental stress responses, vascular tissue development, floral organ initiation, organ size, flowering time, and pollen wall development, [7-9, 13, 19, 20, 23, 26, 29, 34, 35, 39-42, 47, 51, 52]. Out of 29 Arabidopsis $A H L$ gene family members, 13 have been characterized; AtAHL1, AtAHL3, AtAHL4, AtAHL10, AtAHL15,
AHL16, AtAHL18, AtAHL19, AtAHL20, AtAHL22, AtAHL25, AtAHL27 and AtAHL29 [12, 19, 28, 29, 34, $35,39,40,43,47,53]$. Interestingly, several of the functionally characterized AHLs (AtAHL16, AtAHL18, AtAHL22, AtAHL27 and AtAHL29) have been directly or indirectly implicated in the regulation of flowering time in a redundant manner [40-42, 47]. AtAHL16, AtAHL18, AtAHL22, AtAHL27 and AtAHL29 are all Clade-A AHLs [49].

In this study, we used a gain-of-function analysis strategy to avoid potential issues associated with genetic redundancy to characterize AtAHL20 (AT4G14465), a Clade-A AHL. AtAHL2O was initially selected for functional analysis together with AtAHL6 (Clade-B AHL gene family member) as part of a comparative functional characterization study between $A H L s$ that belong to two distinct phylogenetic clades and contain different AThook domain types. That work is ongoing; therefore, this study only focuses on AtAHL20. Transgenic plants overexpressing AtAHL2O flowered later than the wild type in long-day (LD) and short-day (SD) conditions. Transcript abundance analysis of the key flowering time regulator, FLOWERING LOCUS T (FT), showed that its expression was repressed in 35S:AtAHL20 plants. In addition, FT's redundant homologue, TSF, and other downstream flowering pathway genes, $A G L 8$ and SPL3, were also repressed in 35S:AtAHL20 plants. We demonstrated that the second arginine residue in the conserved R-G-R core motif in the AT-hook domain was important for the manifestation of AtAHL20's overexpression phenotypes. Targeted yeast-two hybrid assay results showed that AtAHL20 interacted with itself, its closest family member AtAHL19, as well as other Clade-A AHLs, AtAHL22 and AtAHL29, which have previously been shown to regulate flowering time. Overall, we demonstrated that AtAHL2O is a photoperiod-independent repressor of FT expression and other downstream flowering pathway genes.

\section{Results \\ AtAHL20 tissue expression pattern}

We analyzed AtAHL20's expression pattern via a transcriptional fusion with the $\beta$-glucuronidase (GUS) reporter gene. Strong global GUS signal was observed in all tissues, including root hairs, suggesting that AtAHL2O is constitutively expressed in seedlings (Fig. 1a). 12-day old pAtAHL20-GUS transgenic plants displayed GUS activity in leaf minor veins and trichomes (Fig. 1b). In floral structures, GUS activity was detected in petals, petal vasculature, anthers, stigma and the upper part of the style, but the signal was weaker in the pedicel and peduncle vasculature (Fig. 1c, d). Semi-quantitative PCR analysis also showed differential AtAHL2O tissue expression pattern in whole seedlings, seedling roots, 

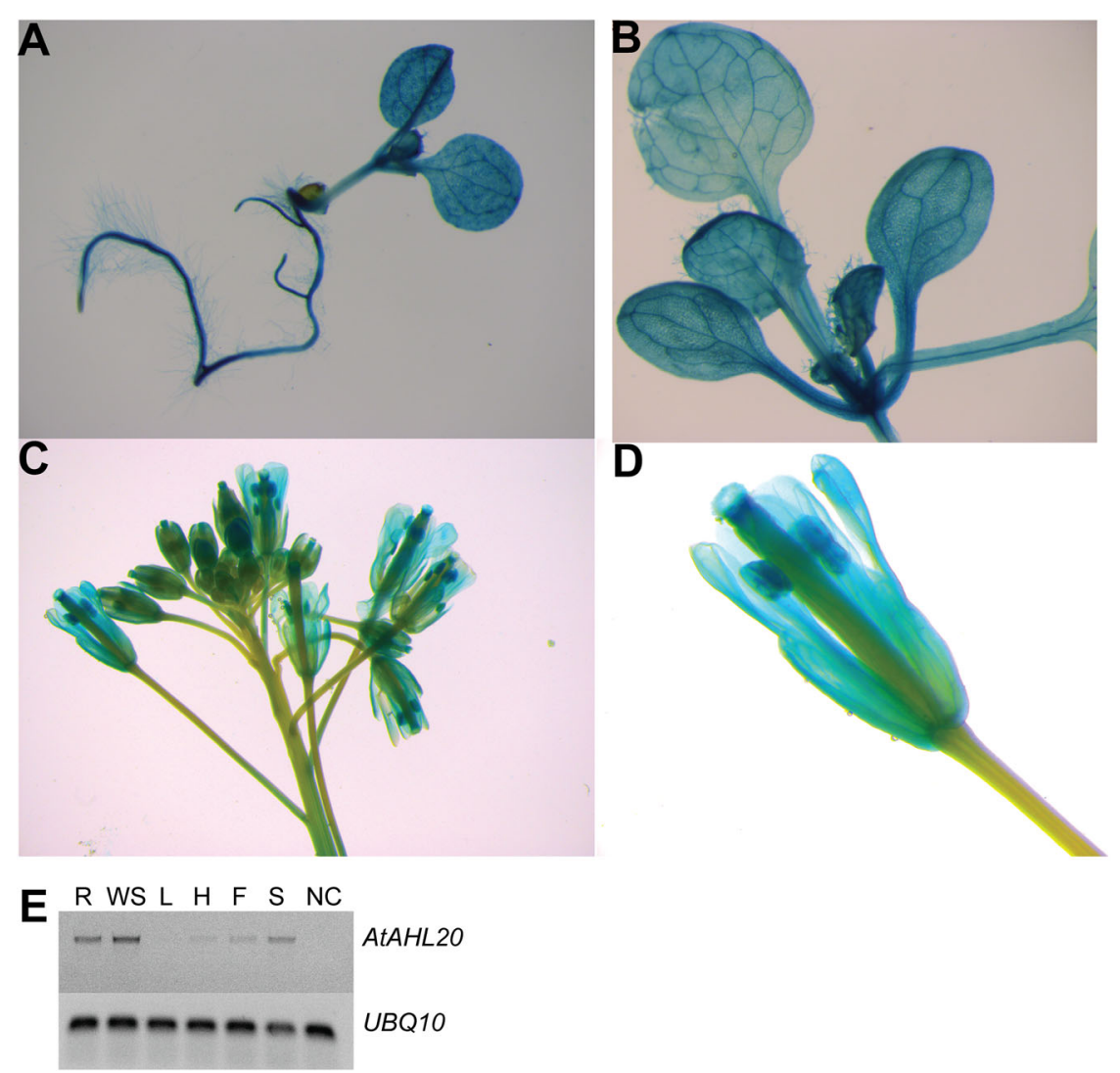

Fig. 1 AtAHL2O promoter-GUS expression pattern. Wild-type Arabidopsis plants were transformed with a construct encoding a pAtAHL20-GUS transcriptional fusion. Histochemical analysis was conducted on 6-day old seedlings grown on Murashige and Skoog (MS) agar plates under continuous white light, rosette leaves from 12-day old plants and floral structures of adult plants grown under LD conditions in the greenhouse. GUS histochemical staining patterns in (a), 6-day old pAtAHL20:GUS seedlings (b), rosette leaves from a 12-day old pAtAHL20:GUS plant showing expression in minor veins (c), pAtAHL20:GUS floral structure (d), close-up of pAtAHL20:GUS floral structure. GUS activity assays were performed three times with similar results. (e) Semi-quantitative PCR gel showing AtAHL20 tissue expression pattern in 7-day old seedling roots (R), 7-day old whole seedling (WS), adult flowering plant rosette leaf (L), 7-day old seedling hypocotyls $(\mathrm{H})$, flower $(\mathrm{F})$, siliques $(\mathrm{S})$ and no reverse transcriptase negative control (NC). UBQ10 was used as a house keeping gene control

hypocotyls, flowers and siliques, a trend similar to GUS histochemical staining pattern (Fig. 1e). Largely, AtAHL20 showed a ubiquitous tissue expression pattern and overlaps with $p F T$-GUS expression pattern in minor veins of young rosette leaves [36].

\section{S:AtAHL20 plants flowered later than the wild type}

Gene overexpression studies and activation-tagging screens have been key tools used to characterize $A H L$ gene function $[28,35,40,43]$. Multiple independent transgenic plants overexpressing AtAHL2O displayed a dwarf phenotype (Fig. 2a, b) and a late-flowering phenotype compared to the wild type and ahl20-1/ahl20-2 TDNA insertion lines under both LDs (Fig. 2c, d) and SDs (Fig. 2e, f). Previously, a conserved arginine amino acid residue in the AT-hook domain was shown to be necessary for AtAHL22 and AtAHL29's gain-of-function phenotypes [35, 47, 49]. Therefore, we next examined whether this was the case for AtAHL20. We generated constructs carrying AtAHL20 coding sequence harboring a point mutation (AtAHL2Om) in the conserved R-G-R core motif, changing arginine residue number 72 to a histidine $(\mathrm{R} 72>\mathrm{H})$. The resultant 35S:AtAHL20m transgenic plants overexpressing the mutant protein lost both the dwarf and late-flowering phenotypes observed in 35S:AtAHL20 plants (Fig. 2a-f). Instead, the 35S: AtAHL20m transgenic plants displayed an earlyflowering phenotype compared to wild-type and T-DNA insertion lines under both SDs and LDs (Fig. 2c-f) suggesting that AtAHL2O is a photoperiod-independent floral repressor. These results imply that the second conserved arginine residue is required for the manifestation of AtAHL20's overexpression phenotypes.

\section{Conserved function of Arabidopsis and Camelina AHL2O orthologues}

Since Arabidopsis and Camelina sativa are closely related Brassicaceae family member species [2, 21], we 

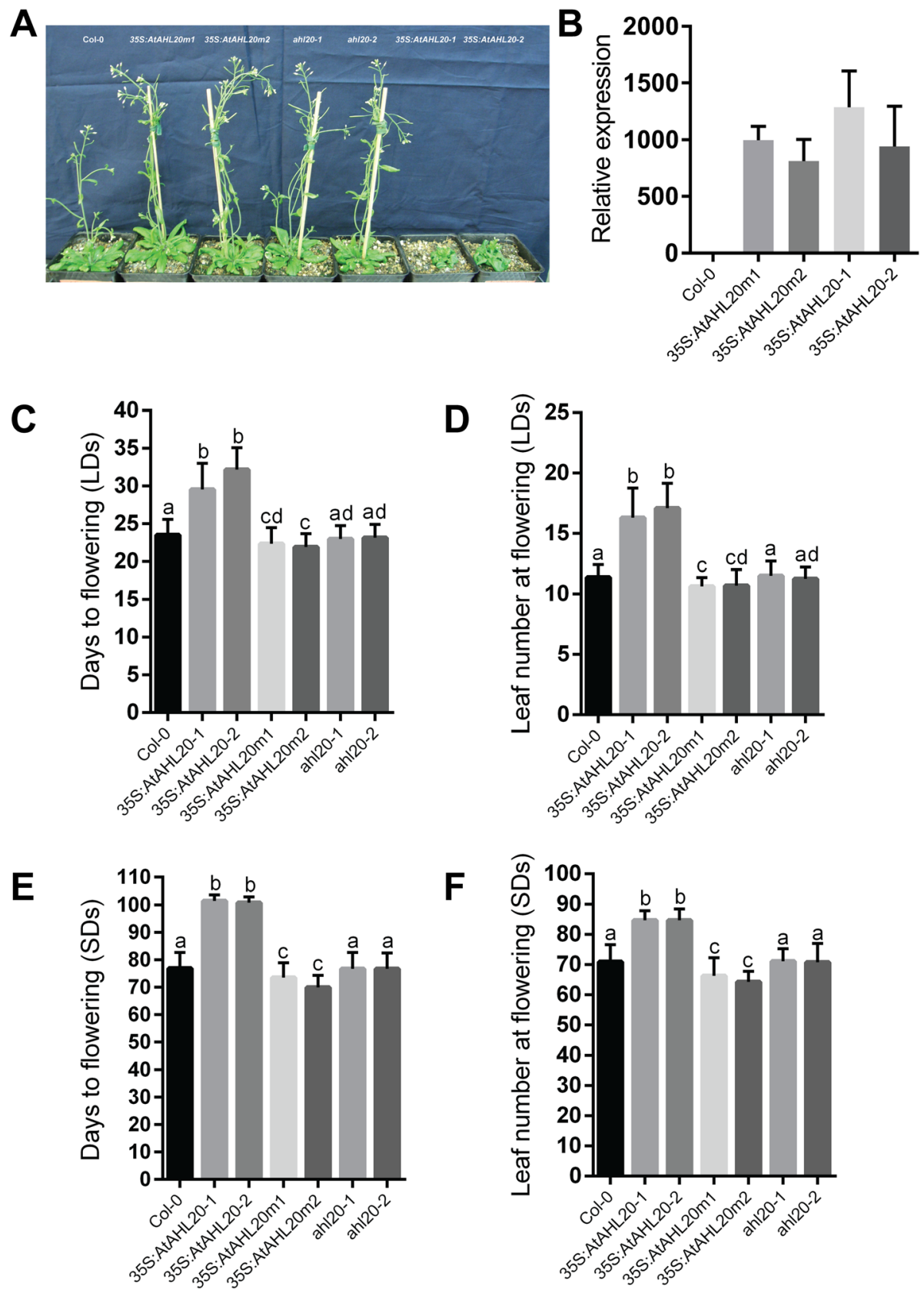

Fig. 2 Phenotypic and flowering-time analysis of 35S:AtAHL20 transgenic plants. a 35S:AtAHL20 transgenic plants displayed dwarf phenotypes compared to the wild type, 35S:AtAHL20m1, 35S:AtAHL20m2, ahl20-1 and ahl20-2 plants under LD conditions. b AtAHL20 expression levels in 355:AtAHL20 and 35S:AtAHL20m plants. c and d 355:AtAHL20-1 and 35S:AtAHL20-2 transgenic plants flowered later than the wild type, 355:AtAHL20m1,35S:AtAHL20m2, ah/20-1 and ahl20-2 plants under LD conditions. e and f 35S:AtAHL20-1 and 35S:AtAHL20-2 transgenic plants flowered later than the wild type, 355:AtAHL20m1, 355:AtAHL20m2, ahl20-1 and ah/20-2 plants under SD conditions. When we overexpressed AtAHL20 protein carnying a point mutation in a conserved R-G-R core motif, the resultant transgenic plants flowered earlier than the wild type (c-f). Flowering time was calculated by counting the number days from sowing until the appearance of a $1 \mathrm{~cm}$ long primary bolt, as well as by counting the total number of primary rosette and cauline leaves present at bolting. The error bar denotes standard deviation (SD). Different letters indicate statistical significance (ANOVA; $P<0.05$ ). $n=$ at least 35 plants (between 35 and 48 plants per genotype). The experiment was repeated three times with similar outcomes

hypothesized that some $A H L$ orthologues would share similar or overlapping biological functions. To test this hypothesis, one of three Camelina AHL20-like copies CsAHL20 (LOC104718987), which has high similarity to
AtAHL2O at the nucleotide and protein sequence level was cloned into a binary vector under the $35 \mathrm{~S} \mathrm{CaMV}$ promoter. The resultant construct was used to transform Camelina sativa (L.) Crantz var. Calena wild-type plants. 
We isolated multiple $\mathrm{T}_{3}$ homozygous single-locus insertion overexpression lines, which exhibited late-flowering and dwarf phenotypes compared to wild-type controls (Fig. 3a). These phenotypes were similar to those observed in 35S:AtAHL20 transgenic plants, inferring that Camelina and Arabidopsis AHL2O genes have similar biological functions.

\section{AtAHL20 represses FT expression}

To further investigate the cause of the late floweringtime phenotype observed in 35S:AtAHL20 transgenic plants, we measured transcript levels of the key regulatory flowering gene, FLOWERING LOCUS T (FT) [4] via reverse transcription quantitative polymerase chain reaction (RT-qPCR). FT transcript levels in 35S:AtAHL20 transgenic plants dropped to $\sim 30 \%$ of wild-type levels (Fig. 4a). This result was similar to that reported in plants overexpressing another Clade-A $A H L$ gene family member, AtAHL22 [40]. In contrast, 35S:AtAHL20m plants contained elevated $F T$ levels compared to both wild-type and 35S:AtAHL20 plants (Fig. 4a), which is consistent with the early-flowering phenotype observed in these plants.

Since 35S:CsAHL2O transgenic Camelina plants displayed a late-flowering phenotype compared to the wild type (Fig. 3a), we hypothesized that this was due to suppression of CsFT expression. RT-qPCR data showed that transcript levels of one of three CsFT genes in 35S: CsAHL2O plants were repressed four-fold compared to wild-type plants (Fig. 3b). Sequence alignment revealed high similarity between $A t F T$ and $C s F T$ nucleotide and peptide sequences.

Transcriptional profiling using high throughput nextgeneration ribonucleic acid (RNA) sequencing (RNA-Seq) is a valuable tool to identify differentially expressed genes on a global level $[45,46]$. To gain further insights into the overall flowering-time pathway transcriptome perturbations in 35S:AtAHL20 transgenic plants compared to wildtype plants, we performed RNA-Seq analysis. Kal's Z-test was performed to identify differentially expressed genes between the wild type and 35S:AtAHL20 transgenic plants (Data S1-2). We identified 1628 downregulated and 2179 upregulated genes in 35S:AtAHL20 transgenic plants compared to the wild type. Gene ontology (GO) analysis [30] was performed based on the down-regulated gene list (Data S1) in 35S:AtAHL20 plants compared to the wild type. This led to the identification of three flowering time regulating genes in a small enriched subset of reproductive development GO terms; AGAMOUS-LIKE 8 (AGL8/ AT5G60910), SQUAMOSA PROMOTER BINDING PROTEIN-LIKE 3 (SPL3/AT2G33810) and TWIN SISTER OF FT (TSF/AT4G20370). This result was confirmed via RT-qPCR analysis, which showed repression of all three genes in 35S:AtAHL20 plants compared to the wild type

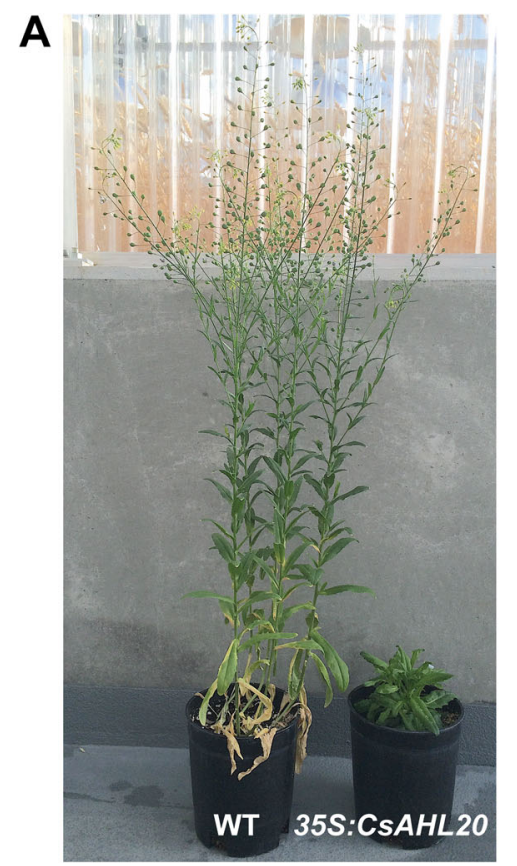

\section{B}

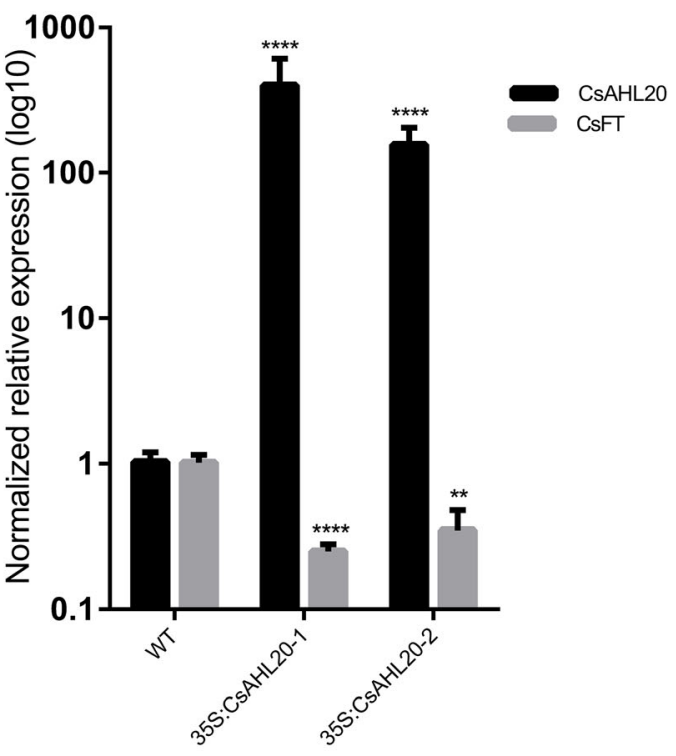

Fig. 3 CSAHL20 overexpression represses CSFT expression in Camelina sativa. a 35S:CSAHL20 plants displayed a dwarf and late-flowering phenotype compared to the wild type. $\mathbf{b}$ Overexpression of CSAHL20 in Camelina sativa wild-type plants resulted in suppressed CsFT transcript levels. T-test statistical analysis was performed using GraphPad Prism software. ${ }^{* * *}=p$-value $<0.0001,{ }^{* * *}=p$-value 0.0001 to $0.001,{ }^{* *}=p$-value 0.001 to $0.01,{ }^{*}=p$ value 0.01 to 0.05 . 3 biological replicates were analyzed $(n=3)$ 


\section{A \\ F T}

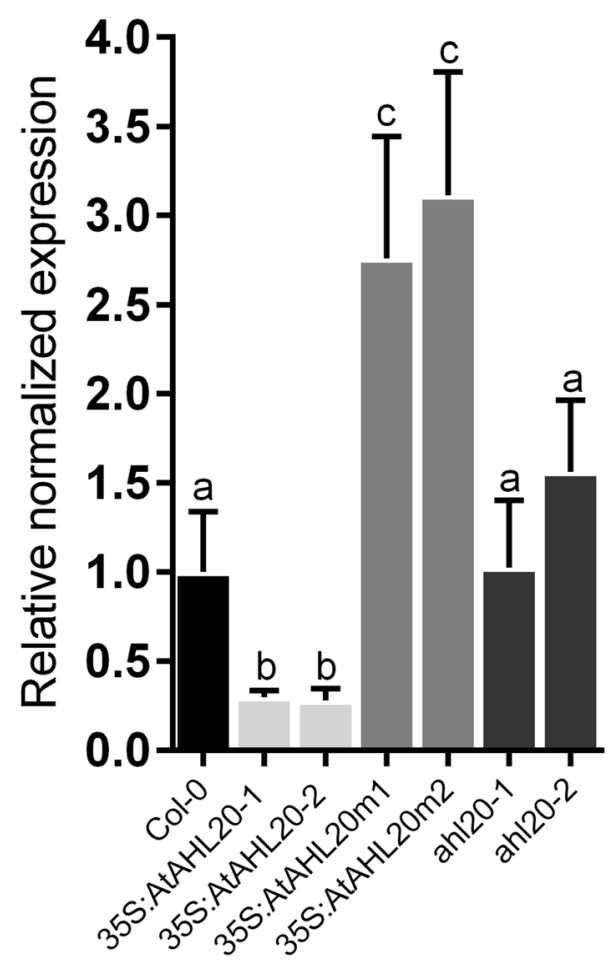

B

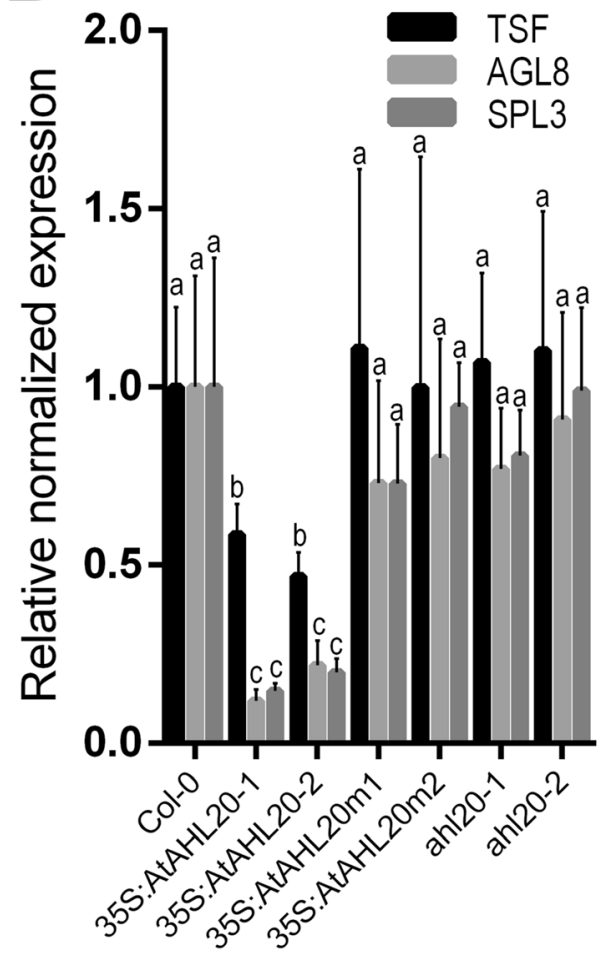

Fig. 4 AtAHL2O overexpression represses $F T$ expression under LD conditions. a $F T$ transcript levels were suppressed to 30\% of wild-type levels in 355:AtAHL20-1 and 355:AtAHL20-2 plants. In contrast, FT transcript abundance was elevated in the dominant-negative mutant plants 35S:AtAHL2Om1 and 35S:AtAHL2Om2, but were unchanged in ahl20-1 and ah/20-2T-DNA insertion lines. b RT-qPCR analysis data showed that AGL8, SPL3 and TSF transcript levels were repressed in 35S:AtAHL20 plants but were unchanged in the wild type and 35S:AtAHL20m1, 35S:AtAHL20m2, ahl20-1 and ahl20-2 plants. RT-qPCR analysis was performed using RNA extracted from rosette leaves of three biological replicates of 21-day old plants grown under LD conditions. The error bar denotes standard error of mean (SEM). Different letters indicate statistical significance (ANOVA; $P<0.05$ )

(Fig. 4b). However, AGL8, SPL3 and TSF transcript accumulation levels were unchanged in 35S:AtAHL20m and ahl20 T-DNA insertion mutant plants (Fig. 4b).

AtAHL20 interacts with other Clade-A AHLs implicated in flowering time regulation

A few AHL proteins have been shown to interact with themselves and other non-AHL proteins $[25,28,35,47$, 49]. Interestingly, several Clade-A AHLs have been associated with flowering time phenotypes, suggesting that genetic redundancy exists among these genes [40-42, 47]. Therefore, we tested whether any Clade-A AHLs formed homo- and/or heterodimers via targeted yeasttwo-hybrid $(\mathrm{Y} 2 \mathrm{H})$ assays. To avoid false positive proteinprotein interactions, yeast transformed with bait protein constructs were plated on synthetic defined (SD) media supplemented with a predetermined inhibitory concentration of $1 \mathrm{mM}$ 3-amino-1,2,4-triazole (3-AT) (Fig. 5a). Successful co-transformation of yeast with the two bait and prey protein constructs was demonstrated by growth on SDII media (Fig. 5b). We showed that AtAHL20 interacted with itself to form a homodimer (Fig. 5c). Next, we tested whether other Clade-A AHLs that have been implicated in flowering time regulation interacted with each other to form heterodimers. Indeed, AtAHL20 interacted with AtAHL19, AtAHL22 and AtAHL29. We further asked whether it was possible that all AHLs interacted with each other and tested for interaction between a Clade-B member AtAHL6, and a Clade-A member AtAHL20. There was no interaction between AtAHL6 and AtAHL20, indicating that not all AHLs interact with each other (Fig. 5c, Table 1).

\section{Discussion}

Overexpression of AtAHL2O confers a late-flowering time phenotype in Arabidopsis

Our gain-of-function study showed that overexpression of AtAHL2O confers a late-flowering time phenotype under both SDs and LDs (Fig. 2). This result is consistent with previous work implicating several Clade-A Arabidopsis AHLs (AtAHL18, AtAHL22, AtAHL27 and 


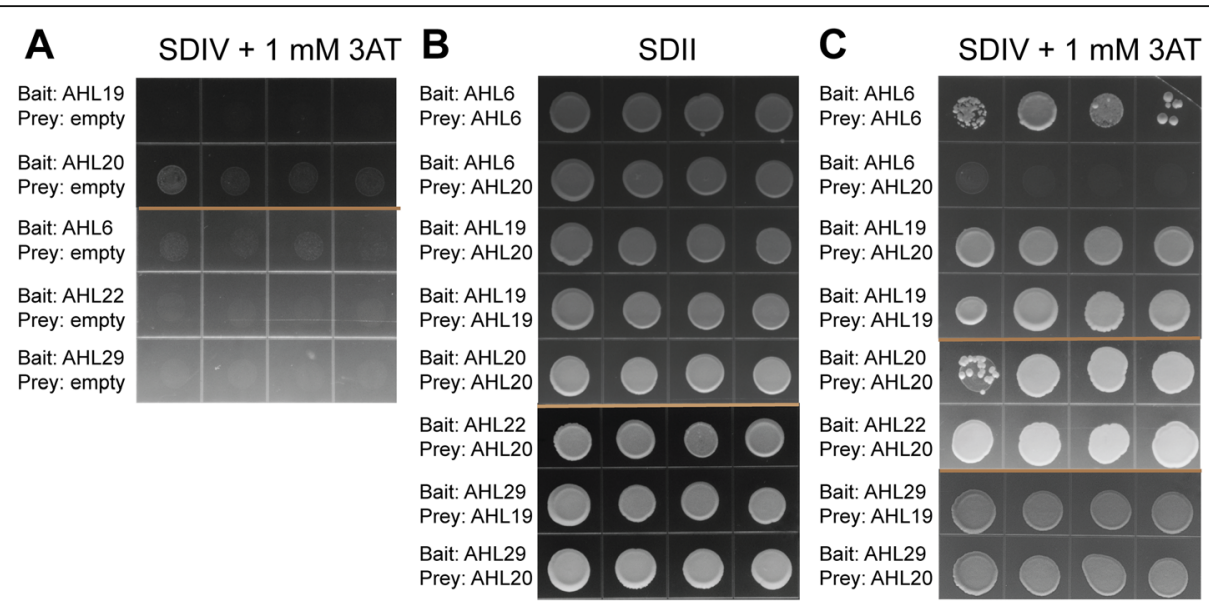

Fig. 5 Targeted yeast-two-hybrid assays. a Targeted yeast hybrid assays were performed between AtAHL20, AtAHL6, AtAHL19, AtAHL22 and AtAHL29. 1 mM 3-amino-1,2,4-triazole (3-AT) was used to suppress auto-activation of bait proteins. $\mathbf{b}$ Yeast cells that were co-transformed with both the bait and prey constructs were plated on synthetic dropout II (SDII) media, which lacked tryptophan and leucine, as positive controls to demonstrate successful transformation. c Four individual colonies were picked and plated on synthetic dropout IV (SDIV) media lacking tryptophan, leucine, histidine, and uracil but supplemented with $1 \mathrm{mM}$ 3-AT to suppress autoactivation. Clade-B member AtAHL6 and Clade-A member AtAHL20 physically interacted with themselves but not with each other. AtAHL20 and its closest family member AtAHL19 physically interacted with each other, as well as themselves. AtAHL20 also interacted with other Clade-A AHLs: AtAHL22 and AtAHL29. These results may suggest that AHLs function redundantly to regulate flowering time, possibly as part of homo-, hetero-dimers or multiple AHLs protein complex that includes AtAHL19 AtAHL20, AtAHL22, and AtAHL29. AtAHL6, a Clade-B member, was used as a control to show that not all AHLs interacted with each other. Light brown lines show demarcation between panels of $\mathrm{Y} 2 \mathrm{H}$ assays that were performed separately, but have been pasted together to make this figure

AtAHL29) in flowering time regulation [35, 40, 47]. Specifically, transgenic plants overexpressing AtAHL22, AtAHL27 and AtAHL29 displayed a late-flowering phenotype [35, 40, 47]. AtAHL22, AtAHL27 and AtAHL29 single gene knockout mutants did not show any clear flowering-time phenotypes. Only when AtAHL27, AtAHL29, AtAHL22 and AtAHL18 were simultaneously knocked out and/or knocked down, did the quadruple mutant display an early-flowering phenotype $[35,40,47]$. These data suggested that several AHLs may function as part of a complex(es) to regulate gene expression $[31,37,47]$ and that functional redundancy exists between these genes and other Clade-A $A H L$ family members. Indeed, Zhao et al. [49] proposed a similar model suggesting that various AHLs formed multi-AHL complexes to regulate hypocotyl growth in Arabidopsis.

Table 1 Yeast two hybrid interactions

\begin{tabular}{llll}
\hline Clade & Bait & Interacting partner & Interaction \\
\hline A/A & AtAHL19 & AtAHL19 & Positive \\
A/A & AtAHL20 & AtAHL20 & Positive \\
A/A & AtAHL20 & AtAHL19 & Positive \\
A/A & AtAHL22 & AtAHL20 & Positive \\
A/A & AtAHL29 & AtAHL20 & Positive \\
A/A & AtAHL29 & AtAHL19 & Positive \\
B/B & AtAHL6 & AtAHL6 & Positive \\
B/A & AtAHL6 & AtAHL20 & Negative \\
\hline
\end{tabular}

Data from our targeted yeast-two-hybrid assays supports this model by demonstrating that AtAHL20 physically interacted with itself and other Clade-A AHL members; AtAHL19, AtAHL22 and AtAHL29 (Fig. 5). It is, therefore, conceivable that these AHLs regulate flowering time as part of a complex. AtAHL20 did not interact with AtAHL6 (a Clade-B $A H L$ ) indicating that not all AHLs interacted with each other. Overall, we have shown that AtAHL20 is the fifth Clade-A AHL to be implicated in flowering time regulation in Arabidopsis.

\section{AtAHL20 is a repressor of $F T$ expression}

Gene expression analyses showed that overexpression of AtAHL2O resulted in depletion of FT transcript levels (Fig. 4). This is not surprising considering that several AHLs, including OsAHL1, AtAHL5, AtAHL10, AtAHL12, AtAHL16, AtAHL20, AtAHL22, AtAHL27 and AtAHL29, have been reported to exhibit promoter binding capabilities or been shown to confer transcriptional repression or activation of downstream target genes $[7,8,10,11$, $19,24,39,41,42,54]$. In particular, a previous study showed that AtAHL2O is a negative regulator of defenses in Arabidopsis [28]. We also showed that an AHL20 orthologue in Camelina repressed CsFT expression, which suggests a conserved function across the two species (Fig. 3). It can be hypothesized that several AHLs modulate gene transcription, individually or as part of protein complexes in Arabidopsis and other species [7, $24,47,49]$. Our studies did not show a direct biological 
mechanistic link between AtAHL20 overexpression and repression of $F T$ transcription. However, a close Clade-A $A H L$ family member, AtAHL22, was shown to repress $F T$ expression via a chromatin remodeling process [47]. This occurs via $F T$ chromatin architecture modification through both $\mathrm{H} 3$ acetylation and methylation. In addition, Favero et al. [7] also showed that AtAHL29, a Clade-A AHL, directly binds to YUC8 and SAUR19 promoters resulting in gene expression repression. Lee and Seo, [24] went further and showed that AtAHL27 and AtAHL29 bind YUC9 promoter and suppress gene expression via chromatin modification activities of SWI2/ SNF2-RELATED 1 (SWR1) complex. Recently, Favero et al. [8] showed that AtAHL29 binds to PIF-targeted loci to reduce binding of PIF to these regions, thereby inhibiting transcriptional activation of growth promoting genes in Arabidopsis petioles. We hypothesize that AtAHL20 may also bind FT promoter elements and suppress its expression, perhaps individually or as part of complex. After all, AtAHL20 has already been shown to have binding affinities for several A/T-containing elements $[10,11]$. A definitive answer to the question of the mechanism of gene repression may be provided via future studies that include yeast-one-hybrid and (chromatin immunoprecipitation) ChIP RT-qPCR experiments. Interestingly, 35S:AtAHL20 plants displayed similar adult plant phenotypes (dwarfism and late flowering) to 35S:AtAHL22 plants (Fig. 2), esc-D/AtAHL27 as well as sob3-D/AtAHL29 [35, 40]. Targeted Y2H studies showed that AtAHL20 interacted with AtAHL22, and SOB3/AtAHL29 (Fig. 5). It is, therefore, plausible that these AHLs function redundantly to regulate flowering time, possibly as part of a complex that includes AtAHL19, AtAHL20, AtAHL22, and AtAHL29.

\section{Missense mutation in the AT-hook domain abolishes AtAHL20's overexpression phenotype}

We hypothesized that a missense mutation in AtAHL20's AT-hook domain would abolish function based on similar outcomes in other Clade-A AHL gene family members, AtAHL29 [35] and AtAHL22 [47]. Thus, it was not surprising that 35S:AtAHL20m transgenic plants (Fig. 2a-f) lost the late-flowering phenotype typically observed when the wild-type AtAHL2O gene is overexpressed. Our working hypothesis based on the works of $[35,47,49]$ is that the second arginine residue in the AT-hook domain's conserved R-G-R core is important for DNA binding, and without it, AtAHL20 would be unable to bind AT-rich DNA and recruit chromatin modifying components required to repress $F T$ transcription. This is in line with a deletion mutant study from $\mathrm{Lu}$ et al., [28] who showed that removal of the entire AT-hook domain abolished AtAHL20's suppression function. This raises an interesting question regarding the specific biological importance of the conserved R-G-R amino acid trio found in both type-1 and type-2 AT-hook motifs, versus peptide sequences flanking the AT-hook domain, for example. Would the mutation of the second arginine in the R-G-R core motif in all three AHL types (Type-I, -II, -III) also abolish overexpression phenotypes observed in transgenic plants overexpressing these genes? What role does the divergent nature of amino acid sequences flanking the R-G-R core play in Clade-A versus Clade-B AHLs? Studies in mammalian AHL orthologues, HMGA proteins, showed that the different types of AThook domains bind DNA with different affinities $[5,18]$. HMGA proteins containing a type-1 AT-hook, similar to the one found in Clade-A AHLs (e.g. AtAHL20, AtAHL22, AtAHL27 and AtAHL29) [49], were found to confer the highest affinity to AT-rich DNA due to the nature of the peptide sequence adjacent to the R-G-R core motif. Interestingly, HMGAs containing a type-2 AT-hook, similar to one found in AtAHL6, have decreased DNA-binding affinity to AT-rich DNA $[5,18]$. Notably, preliminary data from AtAHL6 gain of function studies showed that transgenic plants overexpressing an aberrant gene carrying an R81- $>\mathrm{H}$ mutation (35SAtAHL6m) did not abolish the overexpression phenotype (early-flowering) observed in 35S:AtAHL6 plants. We can thus speculate whether this due to the fact that AtAHL6's AT-hook domain has low DNAbinding affinity to begin with. In the future, it will be important to further investigate the effect of missense mutations in Clade-A versus Clade-B AHLs which contain different At-hook types, and whose conserved R-G-R core is flanked by divergent amino acid sequences.

\section{FT repression by AtAHL20 negatively affects expression of downstream flowering pathway genes}

Quantitative PCR data showed that overexpression of AtAHL20 also resulted in repression of TSF, AGL8 and SPL3 expression (Fig. 4b). AGL8 and SPL3 function downstream of $F T$ in the flowering pathway [16] whereas TSF acts redundantly with $F T$ as a floral pathway integrator [44]. The fact that two redundant floral pathway integrators $F T$ and TSF transcript levels are regulated in a similar manner in 35S: AtAHL20 transgenic plants, raises an interesting question. Does AtAHL2O act directly on these two floral pathway integrators, or act upstream of them. Further experiments, including ChIP-Seq, yeast-one-hybrid assays would help identify AtAHL20's direct targets. Previous work showed that overexpression of AtAHL29, a Clade-A Type-I gene (just like AtAHL20), also caused delayed flowering in Arabidopsis [35]. Interestingly, preliminary Chip-Seq data from our lab showed that AtAHL29 binds FT. Taken together, these data suggest that AtAHL20 may function in a 
similar manner, by directly binding to promoters of its downstream targets.

At the same time, it was interesting that overexpression of an aberrant AtAHL20 protein in 35S:AtAHL20m transgenic plants only resulted in the elevation of $F T$ transcript levels but not in downstream flowering pathway genes TSF, AGL8 and SPL3. We speculate that AtAHL20 indirectly affects expression of downstream targets via the direct repression of the main regulatory component of the flowering pathway, FT. Therefore, perhaps the elevation of $F T$ transcript levels in 35S: AtAHL2Om transgenic plants is not of enough magnitude to dramatically alter the expression of downstream components.

\section{Conclusion}

In conclusion, overexpression of AtAHL20 repressed the expression of flowering pathway genes FT, TSF, AGL8 and SPL3. In contrast, overexpression of an aberrant AtAHL20 protein harboring a missense mutation in the AT-hook domain abolished these phenotypes. These data suggest that AtAHL2O is a transcription factor whose function is partly dependent on a conserved R-G$\mathrm{R}$ core motif in the AT-hook domain.

\section{Methods}

\section{Plant material}

All Arabidopsis thaliana plants are in the Columbia (Col-O) background. Col-O and AtAHL2O T-DNA insertion mutants, ahl20-1 (Salk_144620) and ahl20-2 (Salk_ 148971) seeds used in this study were obtained from the Arabidopsis Biological Resource Center (ABRC). Camelina plants Camelina sativa (L.) Crantz var Calena) were grown in a greenhouse ( $16 \mathrm{~h}$ light and $8 \mathrm{~h}$ dark) at $25^{\circ} \mathrm{C}$. Camelina seeds were provided by Dr. Scot Hulbert of Washington State University, who obtained them from Dr. Stephen Guy at Washington State University [15].

\section{Cloning and generation of transgenic Arabidopsis and Camelina plants Arabidopsis thaliana}

AtAHL20 overexpression Gateway compatible Entry vectors containing Arabidopsis $A H L$ gene coding sequences and other genes used in this study were obtained from ABRC. To overexpress AtAHL20, Gateway Entry vector, pENTR223, was used in Gateway LR reactions (Invitrogen, Carlsbad, CA) with destination vector pEarlyGate100 binary vector (35S constitutive promoter) [6]. The binary vectors carrying AtAHL2O cDNA were used to transform Col-O wild-type plants via the floral dip method [3]. To generate point mutations in AtAHL20's AT-hook domain we used a QuikChange Lightning Site-Directed Mutagenesis Kit (Agilent, Santa
Clara, CA) using Gateway compatible primers (Table 2). pENTR223 vector carrying AtAHL20 cDNA was used as a template during the site-directed mutagenesis reaction. The resulting construct was sequenced to confirm the successful mutation of the arginine residues in the respective coding sequences.

GUS constructs AtAHL20's 1335 bp long promoter region was PCR amplified using Gateway-compatible primers (Table 2) and cloned into the Gateway compatible Entry vector pDONR221 via a BP reaction (Invitrogen, Carlsbad, CA). Following the BP reaction, the resultant Entry vector was sequenced to confirm the absence of mutations. pDONR221 Entry vectors carrying AtAHL20 promoter were cloned into the Gatewaycompatible destination vector pMDC163 (ABRC) via the Gateway LR reaction to generate a promoter: GUS expression binary vector.

Transgenic Arabidopsis plants expressing the abovementioned constructs were generated in the wild type Col-O background via the floral-dip method [3]. Transgenic seeds were screened on $0.5 \times$ Linsmaier and Skoog modified basal medium supplemented with appropriate antibiotics containing $1.0 \%(\mathrm{w} / \mathrm{v})$ phytagel (Sigma-Aldrich), $1.5 \%(\mathrm{w} / \mathrm{v})$ sucrose and under continuous white light at $25^{\circ} \mathrm{C}$ in a Percival E-30B growth chamber.

\section{Camelina sativa}

Overexpression of CsAHL20 CsAHL2O (LOC104718987) coding sequence was extracted from the NCBI database after a BLAST search using AtAHL2O (AT4G14465) sequence as a query. Primers (Table 2) were designed from the extracted sequence and were used to amplify CsAHL20's coding sequence. The amplified PCR product was cloned into pDONR221 Entry vector via Gateway $\mathrm{BP}$ clonase II (Invitrogen, Carlsbad, CA) reaction to generate the pDONR221-CsAHL20 Entry vector. A Gateway LR clonase II (Invitrogen, Carlsbad, CA) reaction between pDONR221-CsAHL20 and the destination vector pUSH21 was performed to generate pUSH42-2. In this construct expression of CsAHL20, coding sequence and the selection marker DsRed were separately driven by CaMV $35 \mathrm{~S}$ promoters. The binary vector was transformed into Agrobacterium tumefaciens strain GV3101 and used for plant transformation via the floral-dip protocol [27]. $\mathrm{T}_{1}$ seeds harvested from transformed plants were illuminated with a green LED light and fluorescent seeds were visually detected under a red filter [27]. Single insertion T-DNA $\mathrm{T}_{2}$ mutants were identified by screening for plants that produced 3:1 fluorescent: nonfluorescent seeds. Homozygous $T_{3}$ pUSH42-2-CsAHL20 plants from single locus insertion lines were used for RT-qPCR analysis. 
Table 2 Primers used for cloning and gene expression studies in the study

\begin{tabular}{|c|c|}
\hline Primer & Sequence \\
\hline \multicolumn{2}{|c|}{ Arabidopsis thaliana } \\
\hline AtAGL8qPCR-F & TGCGCTCCAGAAGAAGGATAAAGC \\
\hline AtAGL8 qPCR-R & TTCCGTCAACGACGATGCACCA \\
\hline AtAHL20CDS-F & ATGGCAAACCCTTGGTGGAC \\
\hline AtAHL20CDS-R & TCAGTAAGGTGGTCTTGCGT \\
\hline AtAHL20-ATTB-F & $\begin{array}{l}\text { GGGGACAAGTTTGTACAAAAAAGCAGGCTTCATGGCAA } \\
\text { ACCCTTGGTGGAC }\end{array}$ \\
\hline $\begin{array}{l}\text { AtAHL20-ATTB- } \\
\text { Rv }\end{array}$ & $\begin{array}{l}\text { GGGGACCACTITGTACAAGAAAGCTGGGTCGTAAGGTG } \\
\text { GTCTTGCGTGGA }\end{array}$ \\
\hline $\begin{array}{l}\text { AtAHL20qPCR- } \\
\text { FW }\end{array}$ & CGTTGAGGTGGTCAACCGTA \\
\hline AtAHL20qPCR-Rv & TTGCCTGCGTCTTGAGAAGT \\
\hline AtFTqPCR-F & CCAAGTCCTAGCAACCCTCA \\
\hline AtFTqPCR-R & TACACTGTTTGCCTGCCAAG \\
\hline $\begin{array}{l}\text { AtMDAR4q PCR- } \\
\text { Fw }\end{array}$ & GCGGTGGCTATATCGGTATGG \\
\hline $\begin{array}{l}\text { AtMDAR4q PCR- } \\
\text { Rv }\end{array}$ & AAAGAGACGTGCCATGCAGTG \\
\hline AtSPL3qPCR-F1 & CTTAGCTGGACACAACGAGAGAAGG \\
\hline AtSPL3qPCR-R1 & GAGAAACAGACAGAGACACAGAGGA \\
\hline AtTSFqPCR-F & GAGTCCAAGCAACCCTCACCAA \\
\hline AtTSFqPCR-R & CACCACAATACGATGAATTCCCGAG \\
\hline UBQ10 -F & GGCCTTGTATAATCCCTGATGAATAAG \\
\hline UBQ10 -R & AAAGAGATAACAGGAACGGAAACATAGT \\
\hline \multicolumn{2}{|l|}{ Promoter-GUS } \\
\hline $\begin{array}{l}\text { AtAHL20Prom- } \\
\text { ATTB-FW }\end{array}$ & $\begin{array}{l}\text { GGGGACAAGTTTGTACAAAAAAGCAGGCTTCTTGTAGC } \\
\text { GGTAAATTGTGGCTTAA }\end{array}$ \\
\hline $\begin{array}{l}\text { AtAHL20Prom- } \\
\text { ATTB-Rv }\end{array}$ & $\begin{array}{l}\text { GGGGACCACTTTGTACAAGAAAGCTGGGTCGATTGACC } \\
\text { AAAAACTGGAAATTCGC }\end{array}$ \\
\hline \multicolumn{2}{|l|}{ Camelina sativa } \\
\hline CSAHL20-FW & AACGGTTACTTAGCCGGGG \\
\hline CSAHL20-RV & GCAGCTATCACCATGACCGA \\
\hline $\begin{array}{l}\text { CSAHL20-ATTB- } \\
\text { FW }\end{array}$ & $\begin{array}{l}\text { GGGGACAAGTTTGTACAAAAAAGCAGGCTATATGTCAA } \\
\text { ACCCTTGGTGGACG }\end{array}$ \\
\hline $\begin{array}{l}\text { CSAHL20-ATTB- } \\
\text { Rv }\end{array}$ & $\begin{array}{l}\text { GGGGACCACTITGTACAAGAAAGCTGGGTCTCAGTATG } \\
\text { GTGGTCGCGCGTG }\end{array}$ \\
\hline CsFT-Fw & AGGAATTCACCGTGTCGTGA \\
\hline CsFT-Rv & CGAGTGTTGAAGTTCTGGCG \\
\hline CSMDAR4-FW & TTGGCGAAATGAGGAGGCTT \\
\hline CSMDAR4-RV & AATGCCATGAGAAGGCGAA \\
\hline
\end{tabular}

\section{Yeast-two-hybrid plasmids}

A GAL4-based Y2H system was used in protein-protein interaction assays [38]. Yeast strain L40ccU3, bait vector (pBTM116-GW-D9) with TRP1 reporter marker and prey vector $(p A C T 2-G W)$ with $L E U$ reporter marker were obtained from Dr. Hanjo Hellmann's lab
(Washington State University, Pullman, WA). Gateway Entry vectors carrying AtAHL6, AtAHL19, AtAHL20, AtAHL22 and AtAHL29's coding sequences genes were used in LR reactions to clone the respective open reading frames into the bait and prey vectors ( $p$ BTM116$G W-D 9)$ and (pACT2-GW), respectively. Competent yeast cells were transformed with bait and prey plasmid constructs using a standard lithium acetate protocol. Transformed yeast competent cells were incubated for three days at $28^{\circ} \mathrm{C}$ on SD minimal medium supplemented with Leu and His (SDII). Four randomly selected colonies were diluted 1:2000 in autoclaved distilled water before $20 \mu \mathrm{L}$ were simultaneously dropped on both SDII and SDIV lacking tryptophan, leucine, histidine and uracil and containing predetermined levels of 3-amino-1, 2, 4-triazol (3-AT). Yeast was incubated at $28{ }^{\circ} \mathrm{C}$ for $3-6$ days.

RNA extraction, cDNA synthesis, RT-qPCR, semiquantitative PCR and data analysis

Total RNA was extracted from 10-day old Camelina seedlings grown on $1 / 2 \times \mathrm{MS}$ medium using Plant RNA mini kit (Qiagen, Valencia, CA) according to manufacturer's recommendations. For Arabidopsis, total RNA was extracted from rosette leaves collected from 21-day old adult plants (analyzed to quantify FT, TSF, AGL8 and SPL3 via RTqPCR), as well as from 7-day old seedling roots, whole 7day old seedling, adult plant rosette leaf, 7-day old seedling hypocotyls, flowers and siliques (used for semiquantitative PCR for AtAHL20 tissue specific expression). On-column DNAse treatment was performed to digest any potential contaminating genomic DNA. Complementary DNA (cDNA) was synthesized from total RNA (500 ng) using the iScript Reverse Transcription Super mix (Bio-Rad, Hercules, CA). RT-qPCR was carried out using Bio-Rad's SSO Advanced Universal SYBR Green Super Mix (Bio-Rad, Hercules, CA) and 10-fold diluted cDNA templates (synthesized above) on a Bio-Rad's CFX96 Touch Real-Time PCR Detection System. Melting curves of SYBR green wells were cross checked to eliminate nonspecific amplification. Data are normalized to MDAR4 messenger ribonucleic acid (mRNA) expression (internal control), and fold changes are displayed relative to control plant lines. Error bars represent standard deviations of technical replicates $(n=3)$. Three biological replicates were used from each plant line.

\section{RNA-Seq library preparation}

Total RNA was extracted from rosette leaves harvested from 21-day old growth-chamber-grown plants using MagJET Plant RNA Purification Kit (Thermo Fisher Scientific, Waltham, MA). The Dynabeads mRNA DIRECT Kit (Thermo Fisher Scientific, Waltham, MA) was used for purification of intact polyadenylated (polyA) mRNA. 
RNA-Seq libraries were prepared using the Ion Total RNA-Seq Kit v2 (Life Technologies, Carlsbad, CA) following the manufacturer's protocol.

RNA-Seq datasets were analyzed using CLC Genomics Workbench software (Qiagen, Valencia, CA). RNA-Seq libraries were constructed from RNA extracted from rosette leaf tissue pooled from three independent plants. Following Kal's Z-test [22], genes were classified as differentially expressed with a False Discovery Rate (FDR) adjusted $p$-value $<0.05$ and a fold-change absolute value $>3$.

\section{Read mapping and differential expression}

Reads which already had adaptor sequences removed by the Torrent Suite ver 4.2.1 sequencing software (Thermo Fisher Scientific, Waltham, MA), were quality trimmed using the default setting in CLC Genomics Workbench 7.5 (Qiagen, Valencia, CA). After preprocessing the RNA-Seq data, the reads were mapped to the TAIR10 version of the Arabidopsis genome using CLC Genomics Workbench 7.5 (Qiagen, Valencia, CA). Read counts for each gene were quantified using the RNA-Seq Analysis tool using the default settings. Differential expression of original values was determined with the proportions statistical analysis tool, using Kal's Z-test with FDR correction.

\section{Histochemical GUS analysis}

GUS analysis was performed as described by [48] on sixday old seedlings, 12-day old plants, and floral structures from flowering plants grown in the greenhouse.

\section{Flowering time analysis}

It has been observed that transplanting seedlings to soil can cause stresses that can alter flowering time. Consequently, all seeds were directly sown in pots containing a pre-watered soil mix Sunshine 50 Mix4 (Aggregate) LA4, (Green Island Distributers Inc.; Riverhead, N.Y). These pots were subsequently incubated in darkness for 7 days at $4{ }^{\circ} \mathrm{C}$ to induce near-uniform germination. After that, pots were transferred to growth chambers under the following conditions: white light $\left(200 \mu \mathrm{mol} \mathrm{m}^{-2} \mathrm{~s}^{-1}\right)$, $21^{\circ} \mathrm{C}$ and $60-70 \%$ humidity. Once the seedlings were several days old, they were thinned to one per pot by clipping using small scissors. Experience in the lab suggests that removal of whole seedlings causes root damage to neighboring seedlings, which in turn can cause damage/stress that can potentially lead to altered flowering time. This approach gives the most uniform and repeatable flowering time results for each genotype. To measure flowering time, we counted the number of days from germination time until the floral stem was $0.5 \mathrm{~cm}$ above the basal rosette.

\section{Sequence alignment}

AtAHL20, AtFT, CsAHL20 and CsFT nucleotide and protein sequences were downloaded from NCBI database (Data S3). Both nucleotide and protein sequence alignment were aligned using BOXSHADE public server https://embnet.vital-it.ch/software/BOX_form.html.

\section{Supplementary Information}

The online version contains supplementary material available at https://doi. org/10.1186/s12870-020-02733-5.

Additional file 1: Data S1. RNA-Seq data of genes down-regulated in 35S:AtAHL20 versus the Col-0 wild type. Data S2. RNA-Seq data of genes up-regulated in 35S:AtAHL20 versus the Col-0 wild type.

Additional file 2: Data S3. AtAHL20, CsAHL20, AtFT and CsFT nucleotide and protein sequences used in cloning of overexpression vectors and in sequence alignments.

\section{Abbreviations}

3-AT: 3-amino-1,2,4-triazole; ABRC: Arabidopsis Biological Resource Center; AGL8: AGAMOUS-LIKE 8; AHL: AT-HOOK MOTIF CONTAINING NUCLEAR LOCALIZED; AHL20: AT-HOOK MOTIF CONTAINING NUCLEAR LOCALIZED \#20; ANOVA: Analysis of variance; AT: Adenine Thymine; At: Arabidopsis thaliana; CaMV: Cauliflower mosaic virus; Col-0: Columbia; Cs: Camelina sativa; DNA: Deoxyribonucleic acid; FT: FLOWERING LOCUS T; FDR: False discovery rate; GO: Gene ontology; GUS: ßeta-glucuronidase; HMG: HIGH MOBILITY GROUP; LD: Long days; SD: Short days; MDAR4: MONODEHYDROASCORBATE REDUCTASE 4; mRNA: Messenger Ribonucleic acid; NCBI: National Center for Biotechnology Information; PPC: PLANT AND PROKARYOTE CONSERVED; R-GR-P: Arginine-glycine-arginine-proline; RNA-seq: Ribonucleic acid sequencing; RT-qPCR: Reverse transcription quantitative polymerase chain reaction; SD: Synthetic defined; SEM: Standard error of mean; SPL3: SQUAMOSA PROMOTER BINDING PROTEIN-LIKE 3; T-DNA: Transfer deoxyribonucleic acid; TF: Transcription factor; TSF: TWIN SISTER OF FT

\section{Acknowledgements}

We thank Dr. Hellmann of Washington State University for donating the yeast-two-hybrid library and vectors used in this study. We are also grateful to Dr. Scot Hulbert of Washington State university for donating the Camelina seeds.

\section{Authors' contributions}

R.T. and M.M.N designed the research. R.T., P.S.K, C.F.P. and B.E.W. performed the experiments. R.T. generated all constructs used in Arabidopsis studies. P.S-K. generated constructs used in Camelina sativa studies. P.S.K. generated and analyzed all Camelina sativa transgenic material. C.F.P. and B.E.W. participated in generating and screening AtAHL2O transgenic material. R.T. and M.M.N. wrote the paper. All authors read and approved the final manuscript.

\section{Funding}

This project was supported by the Agriculture and Food Research Initiative competitive grant \# 2013-67013-21666 of the USDA National Institute of Food and Agriculture (to M.M.N.), the USDA National Institute of Food and Agriculture, HATCH project \# 1007178 (to M.M.N.), and the Brubbaken and Reinbold Monocot Breeding Fund (to M.M.N.). This project was also supported by the Global Plant Sciences Initiative Research Fellowship (Washington State University, to R.T.). The funders did not play a role in the design of the study and collection, analysis, and interpretation of data and in writing the manuscript.

\section{Availability of data and materials}

The RNA-Seq dataset(s) supporting the conclusions of this article is (are) available in the NCBI Sequence Read Archive (SRA) repository, accession number PRJNA671767 under the following link: https://www.ncbi.nlm.nih. gov/Traces/study/?acc=PRJNA671767 
The datasets used and/or analyzed during the current study are available from the corresponding author on reasonable request.

\section{Ethics approval and consent to participate}

Not applicable.

\section{Consent for publication \\ Not applicable.}

\section{Competing interests}

The authors declare that they have no competing interests.

\section{Author details}

${ }^{1}$ Program in Molecular Plant Sciences, Washington State University, Pullman, WA 99164, USA. ²Department Crop and Soil Sciences, Washington State University, Pullman, WA 99164, USA. ${ }^{3}$ Present address: Plant Sciences and Horticultural Landscape Department, University of Maryland, College Park, MD 20742, USA. ${ }^{4}$ Present address: Washington State Department of Fish and Wildlife, Olympia, WA 987501, USA. ${ }^{5}$ Present address: United States Department of Agriculture, Animal and Plant Health Inspection Service, Wildlife Services, National Wildlife Research Center, Fort Collins, CO 80521, USA. ${ }^{6}$ Present address: Washington State University College of Nursing, Spokane, WA 99202, USA.

Received: 6 July 2020 Accepted: 9 November 2020

Published online: 11 December 2020

\section{References}

1. Aravind $L$, Landsman D. AT-hook motifs identified in a wide variety of DNAbinding proteins. Nucleic Acids Res. 1998;26:4413-21.

2. Beilstein MA, Al-Shehbaz IA, Mathews S, Kellogg EA. Brassicaceae phylogeny inferred from phytochrome a and ndhF sequence data: tribes and trichomes revisited. Am J Bot. 2008;95:1307-27.

3. Clough SJ, Bent AF. Floral dip: a simplified method for agrobacteriummediated transformation of Arabidopsis thaliana. Plant J. 1998;16:735-43.

4. Corbesier L, Vincent C, Jang S, Fornara F, Fan Q, Searle I, Giakountis A, Farrona S, Gissot L, Turnbull C, Coupland G. FT protein movement contributes to long-distance signaling in floral induction of Arabidopsis. Science. 2007;316:1030-3.

5. Dragan Al, Liggins JR, Crane-Robinson C, Privalov PL. The energetics of specific binding of AT-hooks from HMGA1 to target DNA. J Mol Biol. 2003; 327:393-411.

6. Earley KW, Haag JR, Pontes O, Opper K, Juehne T, Song K, Pikaard CS. Gateway-compatible vectors for plant functional genomics and proteomics. Plant J. 2006;45:616-29.

7. Favero DS, Jacques CN, Iwase A, Le KN, Zhao J, Sugimoto K, Neff MM. Suppressor of phytochrome B4-\#3 represses genes associated with Auxin signaling to modulate hypocotyl growth. Plant Physiol. 2016;171:2701-16.

8. Favero DS, Kawamura A, Shibata M, Takebayashi A, Jung JH, Suzuki T, Jaeger KE, Ishida T, Iwase A, Wigge PA, Neff MM, Sugimoto K. AT-hook transcription factors restrict petiole growth by antagonizing PIFs. Curr Biol. 2020;30(8): 1454-1466.e6.

9. Favero DS, Le KN, Neff MM. Brassinosteroid signaling converges with suppressor of phytochrome B4-\#3 to influence the expression of small auxin up RNA genes and hypocotyl growth. Plant J. 2017:89:1133-45.

10. Franco-Zorrilla JM, Lopez-Vidriero I, Carrasco JL, Godoy M, Vera P, Solano R. DNA-binding specificities of plant transcription factors and their potential to define target genes. Proc Natl Acad Sci U S A. 2014;111:2367-72.

11. Franco-Zorrilla JM, Solano R. High-throughput analysis of protein-DNA binding affinity. Methods Mol Biol. 2014;1062:697-709.

12. Fujimoto S, Matsunaga S, Yonemura M, Uchiyama S, Azuma T, Fukui K. Identification of a novel plant MAR DNA binding protein localized on chromosomal surfaces. Plant Mol Biol. 2004;56:225-39.

13. Gallavotti A, Malcomber S, Gaines C, Stanfield S, Whipple C, Kellogg E, Schmidt RJ. Barren stalk fastigiate1 is an AT-hook protein required for the formation of maize ears. Plant Cell. 2011;23:1756-71.

14. Gordon BR, Li Y, Cote A, Weirauch MT, Ding P, Hughes TR, Navarre WW, Xia $B$, Liu J. Structural basis for recognition of AT-rich DNA by unrelated xenogeneic silencing proteins. Proc Natl Acad Sci U S A. 2011;108:10690-5.
15. Guy SO, Wysocki DJ, Schillinger WF, Chastain TG, Karow RS, GarlandCampbell K, Burke IC. Camelina: adaptation and performance of genotypes. Field Crop Res. 2014;155:224-32.

16. Higgins JA, Bailey PC, Laurie DA. Comparative genomics of flowering time pathways using Brachypodium distachyon as a model for the temperate grasses. PLoS One. 2010;5:e10065.

17. Himes SR, Reeves R, Attema J, Nissen M, Li Y, Shannon MF. The role of highmobility group I(Y) proteins in expression of IL-2 and T cell proliferation. J Immunol. 2000;164:3157-68.

18. Huth JR, Bewley CA, Nissen MS, Evans JN, Reeves R, Gronenborn AM, Clore GM. The solution structure of an HMG-I(Y)-DNA complex defines a new architectural minor groove binding motif. Nat Struct Biol. 1997:4:657-65.

19. Jia QS, Zhu J, Xu XF, Lou Y, Zhang ZL, Zhang ZP, Yang ZN. Arabidopsis AThook protein TEK positively regulates the expression of arabinogalactan proteins for Nexine formation. Mol Plant. 2014a;8:251-60.

20. Jin Y, Luo Q, Tong H, Wang A, Cheng Z, Tang J, Li D, Zhao X, Li X, Wan J, Jiao Y, Chu C, Zhu L. An AT-hook gene is required for Palea formation and floral organ number control in rice. Dev Biol. 2011;359:277-88.

21. Kagale S, Koh C, Nixon J, Bollina V, Clarke WE, Tuteja R, Spillane C, Robinson SJ, Links MG, Clarke C, Higgins EE, Huebert T, Sharpe AG, Parkin IA. The emerging biofuel crop Camelina sativa retains a highly undifferentiated hexaploid genome structure. Nat Commun. 2014;5:3706.

22. Kal AJ, van Zonneveld AJ, Benes $\mathrm{V}$, van den Berg M, Koerkamp MG Albermann K, Strack N, Ruijter JM, Richter A, Dujon B, Ansorge W, Tabak HF. Dynamics of gene expression revealed by comparison of serial analysis of gene expression transcript profiles from yeast grown on two different carbon sources. Mol Biol Cell. 1999;10:1859-72.

23. Kim HB, Oh CJ, Park YC, Lee Y, Choe S, An CS, Choi SB. Comprehensive analysis of AHL homologous genes encoding AT-hook motif nuclear localized protein in rice. BMB Rep. 2011;44:680-5.

24. Lee K, Seo PJ. Coordination of matrix attachment and ATP-dependent chromatin remodeling regulate auxin biosynthesis and Arabidopsis hypocotyl elongation. PLoS One. 2017;12:e0181804.

25. Lim PO, Kim Y, Breeze E, Koo JC, Woo HR, Ryu JS, Park DH, Beynon J, Tabrett A, Buchanan-Wollaston $\mathrm{V}$, Nam HG. Overexpression of a chromatin architecture-controlling AT-hook protein extends leaf longevity and increases the post-harvest storage life of plants. Plant J. 2007;52:1140-53.

26. Lou Y, Xu XF, Zhu J, Gu JN, Blackmore S, Yang ZN. The tapetal AHL family protein TEK determines nexine formation in the pollen wall. Nat Commun. 2014,5:3855

27. Lu C, Kang J. Generation of transgenic plants of a potential oilseed crop Camelina sativa by agrobacterium-mediated transformation. Plant Cell Rep. 2008;27:273-8.

28. Lu H, Zou Y, Feng N. Overexpression of AHL20 negatively regulates defenses in Arabidopsis. J Integr Plant Biol. 2010;52:801-8.

29. Matsushita A, Furumoto T, Ishida S, Takahashi Y. AGF1, an AT-hook protein, is necessary for the negative feedback of AtGA3ox1 encoding GA 3-oxidase. Plant Physiol. 2007;143:1152-62.

30. Proost $S$, Van Bel M, Vaneechoutte $D$, Van de Peer $Y$, Inze D, Mueller-Roeber B, Vandepoele K. PLAZA 3.0: an access point for plant comparative genomics. Nucleic Acids Res. 2015;43:D974-81.

31. Reeves R. Nuclear functions of the HMG proteins. Biochim Biophys Acta. 2010;1799:3-14.

32. Reeves R, Nissen MS. The a.T-DNA-binding domain of mammalian high mobility group I chromosomal proteins. A novel peptide motif for recognizing DNA structure. J Biol Chem. 1990;265:8573-82.

33. Rodriguez J, Mosquera J, Couceiro JR, Vazquez ME, Mascarenas JL. The AThook motif as a versatile minor groove anchor for promoting DNA binding of transcription factor fragments. Chem Sci. 2015;6:4767-71.

34. Sirl M, Snajdrova T, Gutierrez-Alanis D, Dubrovsky JG, Vielle-Calzada JP, Kulich I, Soukup A. At-hook motif nuclear localised protein 18 as a novel modulator of root system architecture. Int J Mol Sci. 2020;21:1886.

35. Street $\mathrm{H}$, Shah PK, Smith AM, Avery N, Neff MM. The AT-hook-containing proteins SOB3/AHL29 and ESC/AHL27 are negative modulators of hypocotyl growth in Arabidopsis. Plant J. 2008;54:1-14.

36. Takada S, Goto K. Terminal flower2, an Arabidopsis homolog of heterochromatin protein1, counteracts the activation of flowering locus $T$ by constans in the vascular tissues of leaves to regulate flowering time. Plant Cell. 2003;15:2856-65.

37. Tetko IV, Haberer G, Rudd S, Meyers B, Mewes HW, Mayer KF. Spatiotemporal expression control correlates with intragenic scaffold matrix 
attachment regions (S/MARs) in Arabidopsis thaliana. PLoS Comput Biol. 2006;:2:e21.

38. Weber H, Bernhardt A, Dieterle M, Hano P, Mutlu A, Estelle M, Genschik P, Hellmann H. Arabidopsis AtCUL3a and AtCUL3b form complexes with members of the BTB/POZ-MATH protein family. Plant Physiol. 2005;137:83-93.

39. Wong MM, Bhaskara GB, Wen TN, Lin WD, Nguyen TT, Chong GL, Verslues PE. Phosphoproteomics of Arabidopsis highly ABA-Induced1 identifies AThook-Like10 phosphorylation required for stress growth regulation. Proc Natl Acad Sci U S A. 2019;116:2354-63.

40. Xiao C, Chen F, Yu X, Lin C, Fu YF. Over-expression of an AT-hook gene, AHL22, delays flowering and inhibits the elongation of the hypocotyl in Arabidopsis thaliana. Plant Mol Biol. 2009;71:39-50.

41. Xu Y, Gan ES, Ito T. The AT-hook/PPC domain protein TEK negatively regulates floral repressors including MAF4 and MAF5. Plant Signal Behav. 2013a;8:e25006.

42. Xu Y, Wang Y, Stroud H, Gu X, Sun B, Gan ES, Ng KH, Jacobsen SE, He Y, Ito T. A matrix protein silences transposons and repeats through interaction with retinoblastoma-associated proteins. Curr Biol. 2013b;23:345-50.

43. Yadeta KA, Hanemian M, Smit P, Hiemstra JA, Pereira A, Marco Y, Thomma BP. The Arabidopsis thaliana DNA-binding protein AHL19 mediates verticillium wilt resistance. Mol Plant-Microbe Interact. 2011;24:1582-91.

44. Yamaguchi A, Kobayashi Y, Goto K, Abe M, Araki T. Twin sister of FT (TSF) acts as a floral pathway integrator redundantly with FT. Plant Cell Physiol. 2005:46:1175-89.

45. Yang C, Wei H. Designing microarray and RNA-Seq experiments for greater systems biology discovery in modern plant genomics. Mol Plant. 2015;8: 196-206.

46. Yang SY, Hao DL, Song ZZ, Yang GZ, Wang L, Su YH. RNA-Seq analysis of differentially expressed genes in rice under varied nitrogen supplies. Gene. 2015;555:305-17.

47. Yun J, Kim YS, Jung JH, Seo PJ, Park CM. The AT-hook motif-containing protein AHL22 regulates flowering initiation by modifying flowering locus T chromatin in Arabidopsis. J Biol Chem. 2012:287:15307-16.

48. Zhang J, Vankova R, Malbeck J, Dobrev PI, Xu Y, Chong K, Neff MM. AtSOFL1 and AtSOFL2 act redundantly as positive modulators of the endogenous content of specific cytokinins in Arabidopsis. PLoS One. 2009;4 e8236.

49. Zhao J, Favero DS, Peng H, Neff MM. Arabidopsis thaliana AHL family modulates hypocotyl growth redundantly by interacting with each other via the PPC/DUF296 domain. Proc Natl Acad Sci U S A. 2013;110:E4688-97.

50. Zhao J, Favero DS, Qiu J, Roalson EH, Neff MM. Insights into the evolution and diversification of the AT-hook motif nuclear localized gene family in land plants. BMC Plant Biol. 2014;14:266.

51. Zhao J, Grafi G. The high mobility group I/Y protein is hypophosphorylated in endoreduplicating maize endosperm cells and is involved in alleviating histone H1-mediated transcriptional repression. J Biol Chem. 2000;275: 27494-9.

52. Zhao J, Paul LK, Grafi G. The maize HMGA protein is localized to the nucleolus and can be acetylated in vitro at its globular domain, and phosphorylation by CDK reduces its binding activity to AT-rich DNA. Biochim Biophys Acta. 2009;1789:751-7.

53. Zhou J, Wang X, Lee JY. Cell-to-cell movement of two interacting AT-hook factors in Arabidopsis root vascular tissue patterning. Plant Cell. 2013;25: 187-201.

54. Zhou L, Liu Z, Liu Y, Kong D, Li T, Yu S, Mei H, Xu X, Liu H, Chen L, Luo L. A novel gene OSAHL1 improves both drought avoidance and drought tolerance in rice. Sci Rep. 2016;6:30264.

\section{Publisher's Note}

Springer Nature remains neutral with regard to jurisdictional claims in published maps and institutional affiliations.

Ready to submit your research? Choose BMC and benefit from:

- fast, convenient online submission

- thorough peer review by experienced researchers in your field

- rapid publication on acceptance

- support for research data, including large and complex data types

- gold Open Access which fosters wider collaboration and increased citations

- maximum visibility for your research: over $100 \mathrm{M}$ website views per year

At BMC, research is always in progress.

Learn more biomedcentral.com/submissions 